\title{
POLE MAGNETYCZNE SZYNOPRZEWODÓW PROSTOKĄTNYCH O SKOŃCZONEJ DLUGOŚCI
}

\author{
Tomasz Szczegielniak ${ }^{1}$, Zygmunt Piątek $^{1}$, Dariusz Kusiak ${ }^{2}$ \\ ${ }^{1}$ Politechnika Częstochowska, Wydział Inżynierii Środowiska i Biotechnologii, ${ }^{2}$ Politechnika Częstochowska, Wydział Elektryczny
}

Streszczenie. $W$ artykule przedstawiono nowa analityczna metodę obliczania pola magnetycznego uktadów szyn prostokątnych. Metoda wykorzystuje prawa Biota-Savarta. Zaproponowana metoda pozwala na wyznaczanie rozkładu pola magnetycznego $w$ uktadach równoległych szynoprzewodów prostokatnych o dowolnych wymiarach w tym szynoprzewodów o skończonej dlugości. W szczególności wyznaczono pola magnetyczne w nieekranowanych trójfazowych torach wielkoprądowych z prostokątnymi szynoprzewodami fazowymi i z szynoprzewodem neutralnym.

Słowa kluczowe: szynoprzewód prostokątny, tor wielkoprądowy, pole magnetyczne, metoda analityczna

\section{MAGNETIC FIELD IN RECTANGULAR BUS-BARS OF FINITE LENGTH}

Abstract. This paper presents a new analytical computation method for determining the magnetic field distributions in high-current busducts of rectangular busbars. This method is based on Biot-Savart law. The proposed method allows us to calculate the magnetic field intensity distribution in a set of parallel rectangular busbars of any dimensions including any length. In particular, the magnetic fields in busbars of unshielded three-phase systems with rectangular phase and neutral busbars, and the use of the method are described.

Keywords: rectangular busbar, high-current bus duct, magnetic field, analytical method

\section{Wstęp}

Tory wielkoprądowe $\mathrm{z}$ miedzianymi lub aluminiowymi szynoprzewodami prostokątnymi często są stosowane w rozdzielniach i stacjach elektroenergetycznych ze względu na łatwość ich montażu i eksploatacji. Ich prądy znamionowe osiągają wartości do $10 \mathrm{kA}$, zaś napięcia znamionowe to zazwyczaj 10-30 kV [3, 9]. Typowy tor wielkoprądowy z szynoprzewodami prostokątnymi przedstawiono na rysunku 1.

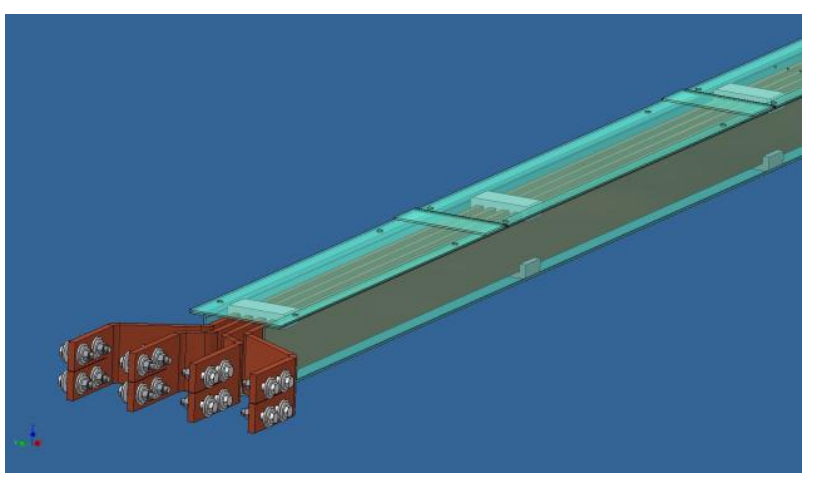

Rys. 1. Tróifazowy tor wielkopradowy z jednym szynoprzewodem prostokatnym na faze $i$ jednym szynoprzewodem neutralnym (Model EB produkowany przez Holduct Mystowice)

Pole magnetyczne generowane przez prądy w torze wielkoprądowym osiąga duże wartości, co może zakłócać pracę sąsiednich urządzeń sterowania i zabezpieczeń jak również niekorzystnie wpływać na zdrowie ludzkie $[1,2,5,10]$. Stąd też dokładne wyznaczenie pola magnetycznego w otoczeniu takich torów wielkoprądowych jest zagadnieniem bardzo ważnym. Rozkład pola magnetycznego o częstotliwości przemysłowej w otoczeniu torów wielkoprądowych może być względnie łatwo wyznaczony jedynie dla przypadków szynoprzewodów rurowych [7] oraz szynoprzewodów prostokątnych o dużych długościach w stosunku do ich wymiarów poprzecznych lub w przypadku przewodów taśmowych $[4,11]$. Zatem celem niniejszego artykułu jest przedstawienie analitycznej metody wyznaczania pola magnetycznego w otoczeniu szynoprzewodów prostokątnych o dowolnych wymiarach poprzecznych jak również dowolnej długości.

\section{Pole magnetyczne szynoprzewodu prostokątnego}

Zakładamy, że w przewodzie prostokątnym o wymiarach $a \times b \times l$ (rys. 2) jest stały lub wolnozmienny prąd sinusoidalny o zespolonej wartości skutecznej $\underline{I}$. Wtedy w każdym punkcie przewodu gęstość prądu jest stała i określona jest wzorem

$$
\underline{J}=\frac{I}{a b}
$$

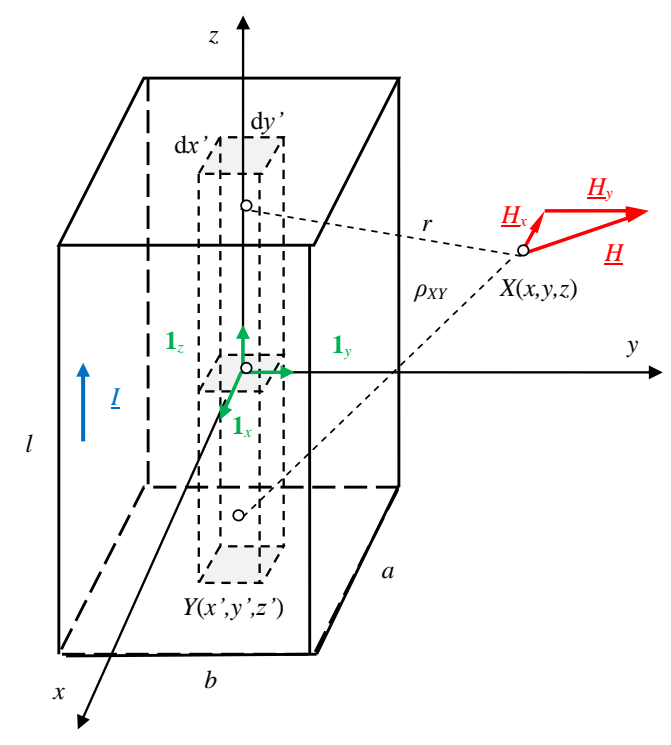

Rys. 2. Szynoprzewód prostokątny o skończonej dtugości

Prąd w obszarze elementarnym $\mathrm{d} s=\mathrm{d} x^{\prime} \mathrm{d} y^{\prime}$ wyraża się wzorem

$$
\mathrm{d} \underline{I}=\underline{J} \mathrm{~d} s=\frac{I}{a b} \mathrm{~d} x^{\prime} \mathrm{d} y^{\prime}
$$

a elementarny wektor pola magnetycznego generowany przez ten prąd opisany jest wzorem [8]

$$
\mathrm{d} \underline{\boldsymbol{H}}=\frac{\mathrm{d} \underline{I}}{2 \pi r} \mathbf{1}_{z} \times \mathbf{1}_{r}=\mathrm{d}_{\underline{H}_{x}} \mathbf{1}_{x}+\mathrm{d} \underline{H}_{y} \mathbf{1}_{y}
$$

Moduł wektora elementarnego możemy zapisać w postaci wzoru

$$
\begin{aligned}
& \mathrm{d} \underline{H}=\frac{\mathrm{d} \underline{I}}{4 \pi r}\left(\cos \alpha_{1}+\cos \alpha_{2}\right)=\frac{\underline{I}}{4 \pi a b} \frac{\mathrm{d} x^{\prime} \mathrm{d} y^{\prime}}{r}\left(\cos \alpha_{1}+\cos \alpha_{2}\right) \\
& \text { gdzie } \cos \alpha_{1}=\frac{\frac{l}{2}+z}{\sqrt{r^{2}+\left(z+\frac{l}{2}\right)^{2}}}, \quad \cos \alpha_{2}=\frac{\frac{l}{2}-z}{\sqrt{r^{2}+\left(z-\frac{l}{2}\right)^{2}}} \text { oraz } \\
& r=\sqrt{\left(x-x^{\prime}\right)^{2}+\left(y-y^{\prime}\right)^{2}} .
\end{aligned}
$$


Wtedy też składowe natężenia elementarnego pola magnetycznego przedstawiamy za pomocą następujących wzorów:

$$
\begin{aligned}
& \mathrm{d} \underline{H}_{x}=-\mathrm{d} \underline{H} \cos \theta=-\mathrm{d} \underline{H} \frac{y-y^{\prime}}{r}= \\
& =-\frac{\underline{I}}{4 \pi a b} \frac{y-y^{\prime}}{r^{2}}\left[\frac{\frac{l}{2}+z}{\sqrt{r^{2}+\left(z+\frac{l}{2}\right)^{2}}}+\frac{\frac{l}{2}-z}{\sqrt{r^{2}+\left(z-\frac{l}{2}\right)^{2}}}\right] \mathrm{d} x^{\prime} \mathrm{d} y^{\prime}
\end{aligned}
$$

oraz

$$
\begin{aligned}
& \underline{\mathrm{d}}_{y}=\mathrm{d} \underline{H} \sin \theta=-\mathrm{d} \underline{H} \frac{x-x^{\prime}}{r}= \\
& =\frac{\underline{I}}{4 \pi a b} \frac{x-x^{\prime}}{r^{2}}\left[\frac{\frac{l}{2}+z}{\sqrt{r^{2}+\left(z+\frac{l}{2}\right)^{2}}}+\frac{\frac{l}{2}-z}{\sqrt{r^{2}+\left(z-\frac{l}{2}\right)^{2}}}\right] \mathrm{d} x^{\prime} \mathrm{d} y^{\prime}
\end{aligned}
$$

zaś długość wektora elementarnego pola wypadkowego

$$
\mathrm{d} \underline{H}=\frac{I}{4 \pi a b} \frac{1}{r}\left[\frac{\frac{l}{2}+z}{\sqrt{r^{2}+\left(z+\frac{l}{2}\right)^{2}}}+\frac{\frac{l}{2}-z}{\sqrt{r^{2}+\left(z-\frac{l}{2}\right)^{2}}}\right] \mathrm{d} x^{\prime} \mathrm{d} y^{\prime}
$$

Wobec powyższego składowe $\underline{H}_{x}$ i $\underline{H}_{y}$ całkowitego wektora natężenia pola magnetycznego $\underline{\boldsymbol{H}}=\underline{H}_{x} \mathbf{1}_{x}+\underline{H}_{y} \mathbf{1}_{y}$ wyznaczymy poprzez następujące całkowania:

$$
\begin{aligned}
& \underline{H}_{x}(x, y)=\int_{-\frac{b}{2}-\frac{a}{2}}^{\frac{b}{2}} \int_{x}^{\frac{a}{2}} \mathrm{~d} \underline{H}_{x} \mathrm{~d} x^{\prime} \mathrm{d} y^{\prime}= \\
& =-\frac{I}{4 \pi a b} \int_{-\frac{b}{2}-\frac{a}{2}}^{\frac{b}{2}} \int_{\frac{a}{2}}^{\frac{a}{2}} \frac{y-y^{\prime}}{\left(x-x^{\prime}\right)^{2}+\left(y-y^{\prime}\right)^{2}}\left(\cos \alpha_{1}+\cos \alpha_{2}\right) \mathrm{d} x^{\prime} \mathrm{d} y^{\prime}
\end{aligned}
$$

oraz

$$
\begin{aligned}
& \underline{H}_{y}(x, y)=\int_{-\frac{b}{2}-\frac{a}{2}}^{\frac{b}{2}} \int_{y}^{\frac{a}{2}} \mathrm{~d} \underline{H}_{y} \mathrm{~d} x^{\prime} \mathrm{d} y^{\prime}= \\
& =\frac{I}{4 \pi a b} \int_{-\frac{b}{2}-\frac{a}{2}}^{\frac{b}{2}} \int_{\frac{a}{2}}^{\frac{a}{2}} \frac{x-x^{\prime}}{\left(x-x^{\prime}\right)^{2}+\left(y-y^{\prime}\right)^{2}}\left(\cos \alpha_{1}+\cos \alpha_{2}\right) \mathrm{d} x^{\prime} \mathrm{d} y^{\prime}
\end{aligned}
$$

zaś moduł pola magnetycznego wypadkowego

$$
\begin{aligned}
& \underline{H}(x, y)=\int_{-\frac{b}{2}-\frac{a}{2}}^{\frac{b}{2}} \int^{\frac{a}{2}} \mathrm{~d} \underline{H} \mathrm{~d} x^{\prime} \mathrm{d} y^{\prime}= \\
& =\frac{\underline{I}}{4 \pi a b} \int_{-\frac{b}{2}-\frac{a}{2}}^{\frac{b}{2}} \int_{\frac{a}{2}}^{\frac{a}{2}} \frac{1}{\sqrt{\left(x-x^{\prime}\right)^{2}+\left(y-y^{\prime}\right)^{2}}}\left(\cos \alpha_{1}+\cos \alpha_{2}\right) \mathrm{d} x^{\prime} \mathrm{d} y^{\prime}
\end{aligned}
$$

W obszarze zewnętrznym przewodu, tzn. dla $x>\frac{a}{2} \cup x<-\frac{a}{2} \cup y>\frac{b}{2} \cup y<-\frac{b}{2}$, punkt obserwacji $X(x, y, z)$ nigdy nie pokryje się $\mathrm{z}$ punktem źródłowym $Y\left(x^{\prime}, y^{\prime}, z^{\prime}\right)$ i powyższe całki są całkami właściwymi. W obszarze wewnętrznym przewodu, tzn. dla $-\frac{a}{2} \leq x \leq \frac{a}{2} \cap-\frac{b}{2} \leq y \leq \frac{b}{2}$, punkt obserwacji $X(x, y, z)$ może pokryć się $\mathrm{z}$ punktem źródłowym $Y\left(x^{\prime}, y^{\prime} z^{\prime}\right)$ i powyższe całki są całkami niewłaściwymi ale zbieżnymi. Problem zbieżności tych całek pojawia się $\mathrm{w}$ drugim całkowaniu. W rozwiązaniu otrzymujemy analityczne wzory na składowe natężenia pola magnetycznego wzdłuż osi $O x$ oraz wzdłuż osi $O y$. Wzory te określają zespolone składowe natężenia pola magnetycznego $\mathrm{w}$ dowolnym punkcie $X(x, y, z)$ wewnątrz $\mathrm{i}$ na zewnątrz prostokątnego przewodu szynowego o skończonej długości. Moduł całkowitego pola magnetycznego wyznaczamy ze wzoru

$$
H(x, y, z)=\sqrt{H_{x}^{2}(x, y, z)+H_{y}^{2}(x, y, z)}
$$

Rozkład modułu pola magnetycznego szynoprzewodu prostokątnego o skończonej długości na płaszczyźnie $x O y$ przedstawiamy na rysunku 3, przy czym pole to jest wyrażone $\mathrm{w}$ jednostkach względnych jako funkcja dana wzorem $h(x, y, z)=\frac{H(x, y, z)}{H_{0}}, \quad$ gdzie natężenia odniesienia $H_{0}=\frac{I}{2(a+b)} . \quad$ Rozkład przestrzenny natężenia pola magnetycznego ilustruje rysunek 4 .

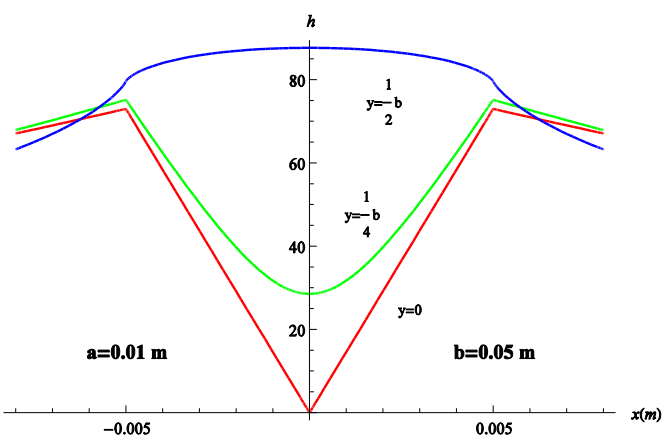

Rys. 3. Rozktad pola $H(x, y, z)$ na ptaszczyźnie $x O y$

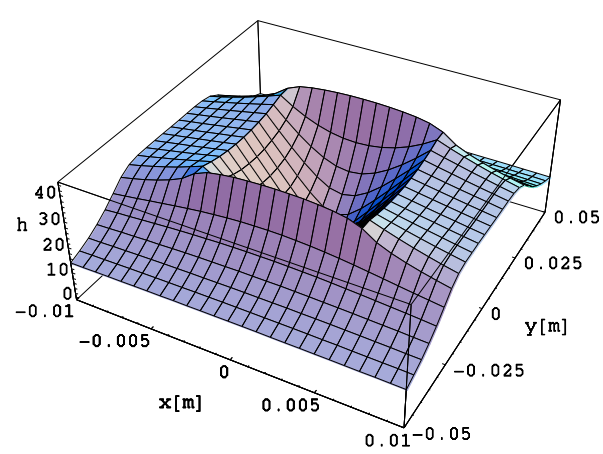

Rys. 4. Rozkład przestrzenny pola $H(x, y, z)$ na płaszczyźnie $z=l / 2$ dla $l=1 \mathrm{~m}, \quad a=0,01 \mathrm{~m}, \quad b=0,05 \mathrm{~m}$

\section{Pole magnetyczne jednofazowego toru wielkoprądowego}

Zakładamy, że w linii o przewodach prostokątnych o wymiarach $a \times b$, długości $l$ i odległości $d$ między nimi (rys. 5) jest stały lub wolnozmienny prąd sinusoidalny o zespolonej wartościach skutecznych $\underline{I}_{1}=\underline{I}$ oraz $\underline{I}_{2}=-\underline{I}$.

Całkowite pole elementarne $\mathrm{w}$ punkcie $X(x, y, z)$ generowane przez prądy $\mathrm{w}$ obszarach elementarnych pierwszego i drugiego przewodu dane jest wzorem

$$
\mathrm{d} \underline{\boldsymbol{H}}=\mathrm{d} \underline{\boldsymbol{H}}_{1}+\mathrm{d} \underline{\boldsymbol{H}}_{2}
$$

zaś pole magnetyczne całkowite w tym punkcie opisuje wzór

$$
\underline{\boldsymbol{H}}=\left(\underline{H}_{x 1}+\underline{H}_{x 2}\right) \mathbf{1}_{x}+\left(\underline{H}_{y 1}+\underline{H}_{y 2}\right) \mathbf{1}_{y}=\underline{H}_{x} \mathbf{1}_{x}+\underline{H}_{y} \mathbf{1}_{y}
$$

We wzorze (11) składowe $\underline{H}_{x 1}$ i $\underline{H}_{y 1}$ dotyczą pola magnetycznego wytworzonego przez prąd $\underline{I}_{1}$. Składowe $\underline{H}_{x 2}$ i $\underline{H}_{y 2}$ 
dotyczą pola magnetycznego wytworzonego przez prąd $\underline{I}_{2}$. Rozkład modułu całkowitego pola magnetycznego, w jednostkach względnych, na płaszczyźnie $x O y$ przedstawiamy na rysunku 6 .

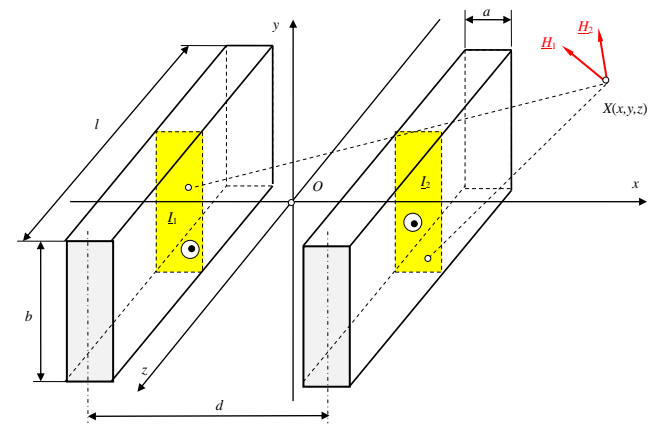

Rys. 5. Jednofazowy tor wielkoprądowy o skończonej dtugości

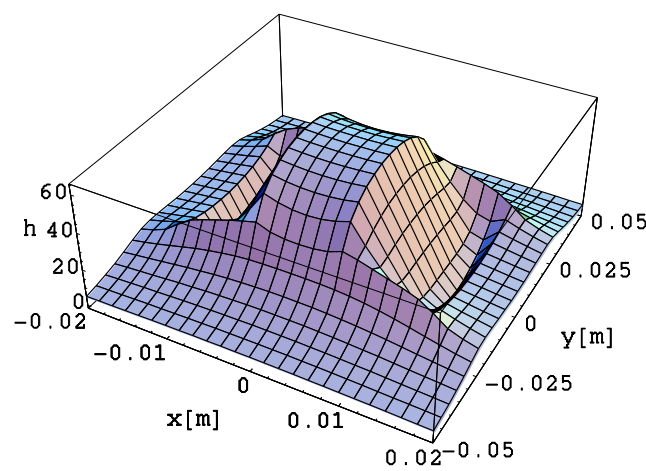

Rys. 6. Rozktad przestrzenny pola $H(x, y, z)$ jednofazowego toru wielkopradowego na ptaszczyźnie $z=l / 2$ dla $l=1 \mathrm{~m}, a=0,01 \mathrm{~m}, b=0,05 \mathrm{~m}, d=2 a$

\section{Pole magnetyczne trójfazowego trójprzewodowego toru wielkoprądowego}

Zakładamy, że w trzyprzewodowej linii trójfazowej o przewodach prostokątnych o wymiarach $a \times b \times l$ (rys. 7) i odległości $d$ między nimi jest stały lub wolnozmienny trójfazowy prąd sinusoidalny o zespolonej wartościach skutecznych $\underline{I}_{1}, \underline{I}_{2}$ oraz $I_{3}$. Całkowite pole elementarne w punkcie $X(x, y, z)$ generowane przez prądy w obszarach elementarnych pierwszego, drugiego i trzeciego przewodu określone jest wzorem

$$
\mathrm{d} \underline{\boldsymbol{H}}=\mathrm{d} \underline{\boldsymbol{H}}_{1}+\mathrm{d} \underline{\boldsymbol{H}}_{2}+\mathrm{d} \underline{\boldsymbol{H}}_{3}
$$

zaś pole magnetyczne całkowite w tym punkcie wyraża się wzorem

$$
\underline{\boldsymbol{H}}=\left(\underline{H}_{x 1}+\underline{H}_{x 2}+\underline{H}_{x 3}\right) \mathbf{1}_{x}+\left(\underline{H}_{y 1}+\underline{H}_{y 2}+\underline{H}_{y 3}\right) \mathbf{1}_{y}=\underline{H}_{x} \mathbf{1}_{x}+\underline{H}_{y} \mathbf{1}_{y}
$$

W powyższym wzorze składowe $\underline{H}_{x 1}$ i $\underline{H}_{y 1}$ wyrażają się odpowiednio wzorami analitycznymi otrzymanymi z (7a) i (7b) po podstawieniu w nich $x+d$ za zmienną $x$ oraz przyjmując prąd $\underline{I}=\underline{I}_{1}$, składowe $\underline{H}_{x 2}$ i $\underline{H}_{y 2}$ wyrażają się odpowiednio tymi samymi wzorami przyjmując w nich prąd $\underline{I}=\underline{I}_{2}$, a składowe $\underline{H}_{x 3}$ i $\underline{H}_{y 3}$ wyrażają się odpowiednio tymi samymi wzorami po podstawieniu w nich $x-d$ za zmienną $x$ i po przyjęciu $\underline{I}=\underline{I}_{3}$.

Rozkład modułu całkowitego pola magnetycznego, w jednostkach względnych, na płaszczyźnie $x O y$ linii trójfazowej trójprzewodowej dla przypadku prądów symetrycznych w szynoprzewodach, czyli dla $\underline{I}_{1}=\underline{I} \mathrm{e}^{\mathrm{j} 0^{\circ}}, \underline{I}_{2}=\underline{I} \mathrm{e}^{-\mathrm{j} 120^{\circ}}$ oraz $\underline{I}_{3}=\underline{I} \mathrm{e}^{\mathrm{j} 120^{\circ}}$, przedstawiamy na rysunku 8 .

Niesymetria prądowa zmienia rozkład pola magnetycznego $\mathrm{w}$ otoczeniu rozpatrywanego toru. Dla przykładu przyjęto następujące prądy fazowe: $\underline{I}_{1}=\underline{I} \mathrm{e}^{\mathrm{j} 0^{\circ}}, \underline{I}_{2}=0,5 \underline{I} \mathrm{e}^{-\mathrm{j} 120^{\circ}} \mathrm{i}$ wtedy
$\underline{I}_{3}=-\underline{I}_{1}-\underline{I}_{2}=0,866 \underline{I} \mathrm{e}^{\mathrm{j} 150^{\circ}}$. Rozkłady pola dla tego przypadku przedstawiono na rysunku 9.

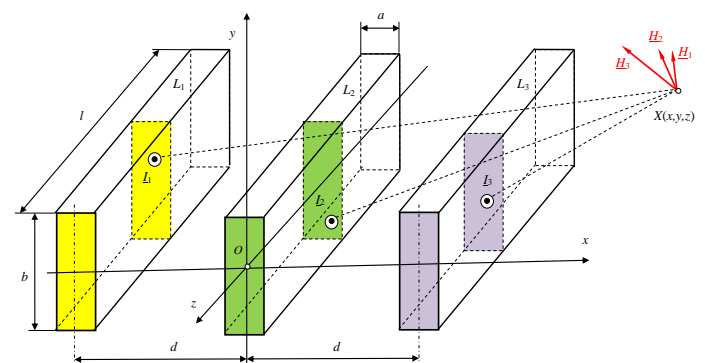

Rys. 7. Trójfazowy trójprzewodowy tor wielkoprądowy o skończonej dlugości

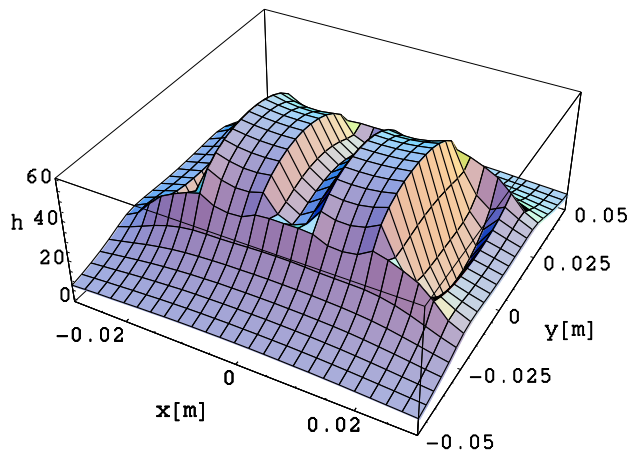

Rys. 8. Rozklad przestrzenny pola $H(x, y, z)$ trójfazowego trójprzewodowego toru wielkoprądowego przy symetrii prądowej na ptaszczyźnie $z=l / 2$ dla $l=1 \mathrm{~m}$, $a=0,01 \mathrm{~m}, b=0,05 \mathrm{~m}, d=2 a$

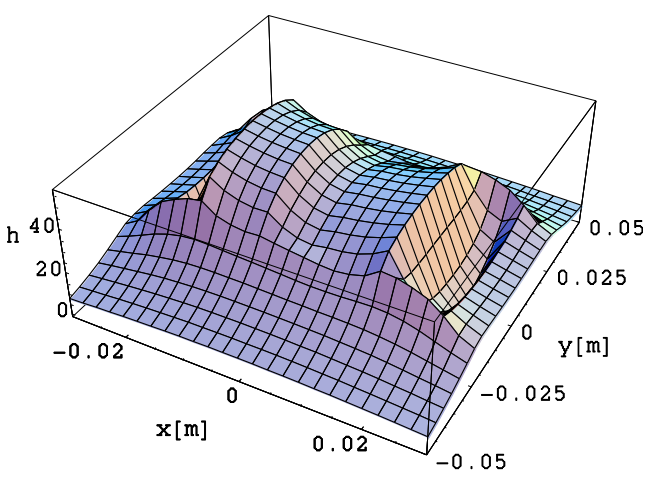

Rys. 9. Rozktad przestrzenny pola $H(x, y, z)$ trójfazowego trójprzewodowego toru wielkoprądowego przy asymetrii prądowej na plaszczyźnie $z=l / 2$ dla $l=1 \mathrm{~m}$, $a=0,01 \mathrm{~m}, b=0,05 \mathrm{~m}, d=2 a$

\section{Pole magnetyczne trójfazowego czteroprzewodowego toru wielkoprądowego}

Rozpatrzmy czteroprzewodowy tor wielkoprądowy o szynoprzewodach prostokątnych (rys. 10) i asymetrii prądowej: $\underline{I}_{1}=\underline{I} \mathrm{e}^{\mathrm{j}^{0^{\circ}}}, \quad \underline{I}_{2}=0,5 \underline{I} \mathrm{e}^{\mathrm{j} 120^{\circ}}, \quad \underline{I}_{3}=\underline{I} \mathrm{e}^{\mathrm{j} 120^{\circ}} \mathrm{i}$ prądem $\mathrm{w}$ szynie neutralnej $\underline{I}_{N}=\underline{I}_{1}+\underline{I}_{2}+\underline{I}_{3}=0.866 \underline{\underline{I}} \mathrm{e}^{\mathrm{j} 150^{\circ}}$.

Wtedy całkowite pole elementarne w punkcie $X(x, y)$ generowane przez prądy w obszarach elementarnych przewodów fazowych i przewodu neutralnego

$$
\mathrm{d} \underline{\boldsymbol{H}}=\mathrm{d} \underline{\boldsymbol{H}}_{1}+\mathrm{d} \underline{\boldsymbol{H}}_{2}+\mathrm{d} \underline{\boldsymbol{H}}_{3}+\mathrm{d} \underline{\boldsymbol{H}}_{N}
$$

zaś całkowite pole magnetyczne w tym punkcie

$\underline{\boldsymbol{H}}=\left(\underline{H}_{x 1}+\underline{H}_{x 2}+\underline{H}_{x 3}+\underline{H}_{x N}\right) \mathbf{1}_{x}+\left(\underline{H}_{y 1}+\underline{H}_{y 2}+\underline{H}_{y 3}+\underline{H}_{y N}\right) \mathbf{1}_{y}=$

$=\underline{H}_{x} \mathbf{1}_{x}+\underline{H}_{y} \mathbf{1}_{y}$

gdzie składowe $\underline{H}_{x 1}$ i $\underline{H}_{y 1}, \underline{H}_{x 2}$ i $\underline{H}_{y 2}$ oraz $\underline{H}_{x 3}$ i $\underline{H}_{y 3}$ wyrażają się odpowiednio wzorami zastosowanymi dla trójfazowego układu trójprzewodowego. 


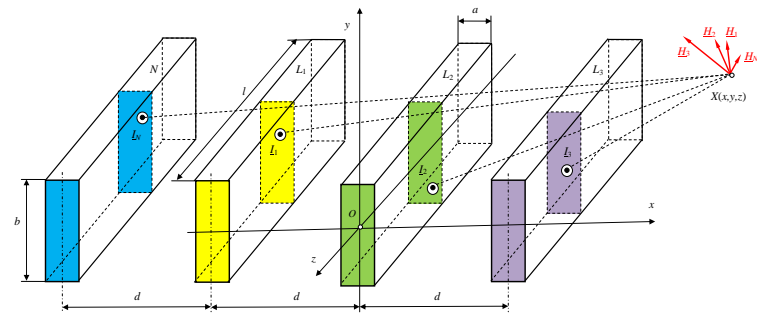

Rys. 10. Trójfazowy czteroprzewodowy tor wielkoprądowy o skończonej dlugości

Składowe $\underline{H}_{x N}$ i $\underline{H}_{y N}$ wyrażają się odpowiednio wzorami otrzymanymi z (7a) i (7b) po podstawieniu w nich $x+2 d$ za zmienną $x$ oraz przyjmując prąd $\underline{I}_{N}=\underline{I}_{1}+\underline{I}_{2}+\underline{I}_{3}$. Rozkłady pola magnetycznego $\mathrm{w}$ takim torze prądowym dla przypadku asymetrii prądowej przedstawiamy na rysunku 11 .

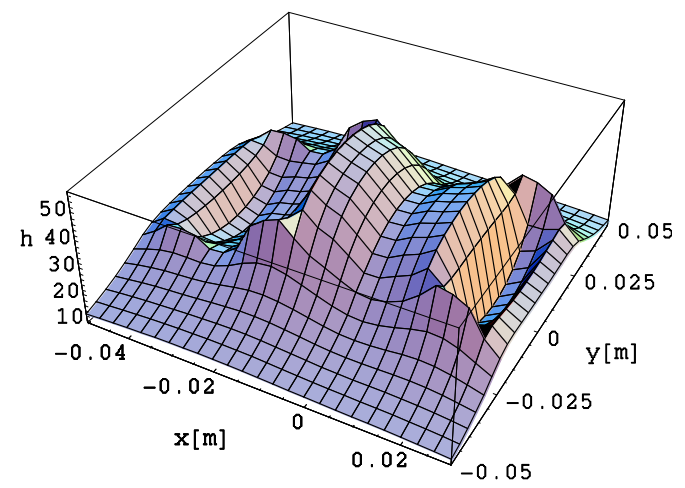

Rys. 11. Rozkład przestrzenny pola $H(x, y, z)$ tróffazowego czteroprzewodowego toru wielkopradowego przy asymetrii prądowej na plaszczyźnie $z=l / 2$ dla $l=1 \mathrm{~m}$ $a=0,01 \mathrm{~m}, b=0,05 \mathrm{~m}, d=2 a$

W celu weryfikacji otrzymanych wyników przeprowadzono symulację korzystając $\mathrm{z}$ programu FEMM [6] opartego na metodzie elementów skończonych. Na rysunku 12 przedstawiono rozkład amplitudy pola magnetycznego przy asymetrii prądowej $\underline{I}_{1}=100 \mathrm{e}^{\mathrm{j} 0^{\circ}}, \underline{I}_{2}=50 \mathrm{e}^{-\mathrm{j} 120^{\circ}}, \underline{I}_{3}=100 \mathrm{e}^{\mathrm{j} 120^{\circ}}$.

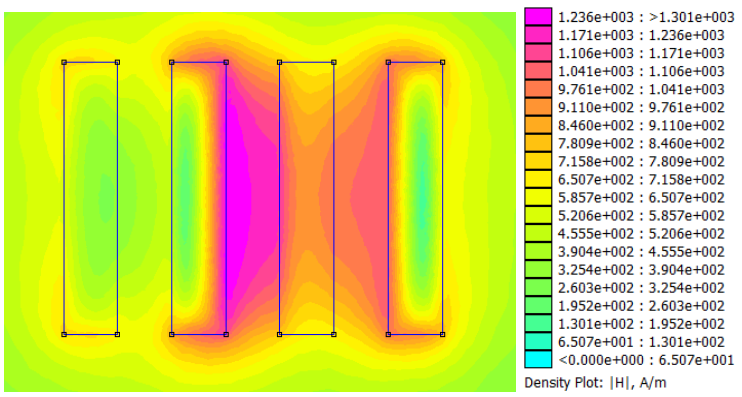

Rys. 12. Rozklad pola magnetycznego przy asymetrii pradowej oraz dla $l=1 \mathrm{~m}$, $a=0,01 \mathrm{~m}, b=0,05 \mathrm{~m}, d=2 a$

\section{Wnioski}

Wyprowadzone wzory umożliwiają obliczanie natężenie pola magnetycznego wytworzone przez prądy szynoprzewodów prostokątnych $\mathrm{w}$ dowolnym punkcie przestrzeni $\mathrm{w}$ tym również w obszarach własnych szynoprzewodów.

Uwzględniają one skończone wymiary poprzeczne i skończoną długość szynoprzewodów. Mogą być stosowane dla dowolnych wartości prądów zespolonych, w szczególności dla przypadków trójfazowych torów wielkoprądowych $\mathrm{z}$ asymetriami prądowymi.
Ponad to $\mathrm{z}$ tych wzorów można otrzymać analityczny opis pola magnetycznego dla długich szynoprzewodów jak również dla przewodów taśmowych.

W przypadku uwzględnienia wpływu zjawisk naskórkowości i zbliżenia na pole magnetyczne torów wielkoprądowych z szynoprzewodami prostokątnymi, wyprowadzone wzory mogą być użyte do opisu pola magnetycznego generowanego przez prądy w tzw. prostokątnych obszarach elementarnych, na które zostają podzielone szynoprzewody badanego toru.

\section{Literatura}

[1] Bottausio O. et al.: Numerical and experimental evaluation of magnetic field generated by power busbar systems. IEE Proc.-Gener. Transm. Distrib., Vol. 143, No. 5, 1996, pp. 455-460.

[2] Cucu M. and Popescu M.O.: Magnetic field in encapsulated bus-bar. U.P.B. Sci Bull., Series C, Vol. 73, Iss. 1, 2011, pp. 129-142.

[3] Ducluzaux A.: Extra losses caused in high current conductors by skin and proximity effects. Schneider Electric "Cahier Technique" no. 83, 1983.

[4] Kazimierczuk M. K.: High-frequency magnetic components. J. Wiley \& Sons, Chichester, 2009.

[5] Keiko T. et al: Calculation of magnetic fields of the bus bar. UPEC'95, Vol. 2, 1995, pp. 554-557.

[6] Meeker, D.C., Finite Element Method Magnetics, version 4.2 (11apr2012, Mathematica Build), http://www.femm.info.

[7] Piątek Z:: Impedances of tubular high current busducts. Polish Academy of Sciences. Warsaw 2008.

[8] Piątek Z., Jabłoński P.: Podstawy teorii pola elektromagnetycznego. WNT, Warszawa 2010.

[9] Sarajčev P., Goič R.: Power loss computation in high-current generator bus ducts of rectangular cross-section. Electric Power Components and Systems, No. 39, 2010, pp. 1469-1485.

[10] Sha X., et al: Analysis of 3-D electromagnetic field for three-phase low voltage and heavy current busbar bridge system. Inter, J. of App. Electromagn. and Mechanics, No.26, 2007, pp. 37-49.

[11] Zhou J., Lewis A.M.: Thin-skin electromagnetic fields around a rectangular conductor bar. J. Phys. D: Appl. Phys., No. 27, 1994, pp. 419-425.

\section{Dr inż. Tomasz Szczegielniak \\ e-mail: szczegielniakt@interia.pl}

Stopień doktora otrzymał w 2011 roku na Wydziale Elektrycznym Politechniki Śląskiej. Obecnie pracuje jako adiunkt w Zakładzie Elektrotechniki i Automatyki w Inżynierii Środowiska Politechniki Częstochowskiej. Jego badania skupiają się na modelowaniu zjawisk elektromagnetycznych w torach wielkoprądowych.

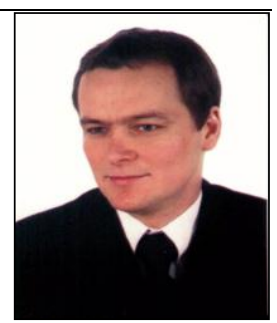

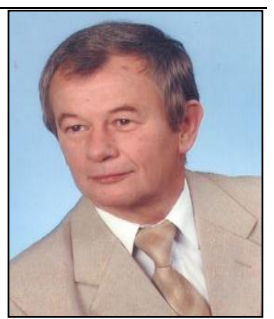

\section{Dr inż. Dariusz Kusiak}

e-mail: dariuszkusiak@wp.pl

Stopień doktora uzyskał w 2008 roku na Wydziale Elektrycznym Politechniki Częstochowskiej. Obecnie pracuje jako adiunkt w Instytucie Elektrotechniki Przemysłowej na Wydziale Elektrycznym Politechniki Częstochowskiej. Jego zainteresowania naukowe to: zagadnienia pola elektromagnetycznego występujące w torach wielkoprądowych oraz szynoprzewodach.

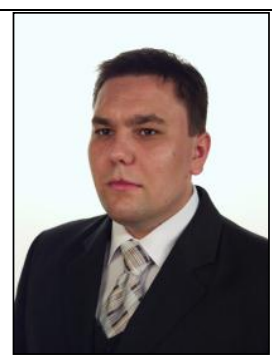

otrzymano/received: 06.06.2013 przyjęto do druku/accepted: 28.10 .2013 